\title{
Sociocultural Theory Applied to Second Language Learning: Collaborative Learning with Reference to the Chinese Context
}

\author{
Zhang Dongyu ${ }^{1}$, Fanyu $^{1} \&$ Du Wanyi ${ }^{1}$ \\ ${ }^{1}$ School of Software, Dalian University of Technology, Dalian, China \\ Correspondence: Software School of Dalian University of Technology Economy and Technology \\ Development Area Dalian City 116620, China. Tel: 86-0411-8458-5281. E-mail: zhangdongyu@dlut.edu.cn
}

$\begin{array}{lc}\text { Received: July 30, } 2013 & \text { Accepted: August 23, } 2013 \quad \text { Online Published: August 29, } 2013 \\ \text { doi:10.5539/ies.v6n9p165 } & \text { URL: http://dx.doi.org/10.5539/ies.v6n9p165 }\end{array}$

The research is financed by the Chinese Society of Academic Degrees and Graduate Education (Grant No. C1-2013Y03-018).

\begin{abstract}
This paper discusses the sociocultural theory (SCT). In particular, three significant concepts of Vyogtsky's theory: self-regulation, the Zone of Proximal Development (ZPD), and scaffolding all of which have been discussed in numerous second language acquisition (SLA) and second language learning (SLL) research papers. These concepts lay the psychological foundation for collaborative learning, the subject of this paper. This publication aims to examine SCT by assessing collaborative learning within the Chinese context. This paper focuses on teacher-student collaboration and it concludes that the perceived way of learning and teaching and teacher-student relationship should be changed in order to implement collaborative learning.
\end{abstract}

Keywords: sociocultural theory, collaborative learning, Chinese context, language learning

\section{Introduction}

In 2010, the Chinese Educational Ministry proposed New National English Curriculum Standards (experimental version) for teaching English as a foreign language in China. These standards are theoretically based on sociocultural theory (SCT) (Cheng, 2012). The change of curriculum standards has become a great concern for Chinese teachers of English as a foreign language (EFL) and language learners, since this may influence their teaching and learning. Therefore, this work sets out to discuss SCT and explore the problems that Chinese teachers have encountered or will face in applying SCT embedded in the new curriculum standards.

Bruner claims that any theory or explanation about human activity should consider its complexity because human people are not isolated, but actually associated with a complex living context:

Explanation of any human condition is so bound to context, so complexly interpretive at so many levels, that it cannot be achieved by considering isolated segments of life in vitro, and it can never be, even at its best, bought to a conclusion beyond the shadow of human doubt. (Luria 1987, p. xii, as cited in Lantolf, 2000).

This view presents the basic principle of SCT. With reference to second language acquisition (SLA) and second language learning (SLL), this approach, conceived by the Soviet psychologist Lev S. Vygotsky, has broadened the understanding of SLA and SLL with a very different perspective. Furthermore, it is becoming one of the mainstreams of SLA research, attracting more and more attention since it provides a psychological base for a number of popular approaches including collaborative (Oxford, 1997; Swain, 2000) and task-based learning (Foley, 1991; Nun, 2001).

It might help provide an overview of SCT by comparing it with the cognitive approach because they correlate with each other. These two approaches are both interested in how learners access linguistic knowledge, that is, linguistic performance rather than linguistic competence that is the focus of UG (Universal Grammar) theorists. However, the theorists of these two approaches hold very different views towards the learning process. Drawing from Donato (2000) this subsequent section will highlight some differences. Firstly, cognitive approach researchers believe that the SLA process can be better understood by working out how the brain processes and learns new information. It emphasizes the acquisition metaphor of language learning and development through 
internal mental process. ON the other hand, SCT stresses the participation metaphor of development. Secondly, for the cognitive approach, individual is the only channel through which knowledge is gained. On the contrary, SCT regards learning as a semiotic process by learner participation in different socially mediated activities. Thirdly, cognitive theorists hold the view that interaction is the sole mechanism to negotiate meaning in the case of linguistic failure. This presents a contrast to SCT that maintains interactions play an important role in language learning and serves as a channel through which learning happens. Finally, from the perspective of research methods, cognitive researchers rely on the post-instructional testing to examine learning, whereas researchers of SCT look for evidence through shared practices of discourse with peers or experts. These comparisons only present some general views of SCT discussions that are more detailed will be presented in the subsequent literature review.

The structure of this paper is as follows: first, there is a discussion of SCT with particular focus on three key concepts of Vygotsky's theory. Secondly, there is an evaluation of SCT from the perspectives of the theory itself and the relevant research carried out. Finally, in the section of the implications of SCT, this paper focuses on the correlation between the teacher-student interaction and SLL learning, which will be investigated and assessed in one of the forms of SCT and collaborative learning, with reference to the Chinese context, before a conclusion is drawn.

\section{Vygotsky's Contributions to Sociocultural Theory}

Vygotsky's theory on language and thinking has received considerable attention in the general psycholinguistic literature. Until the 1990s, some key concepts of his theory (e.g., mediation, regulation, microgenesis, private, and inner speech, and activity theory) showed great impact on SLL. However, a thorough discussion is beyond the scope of this paper and instead, with reference to the topic/concern in this paper, the three concepts of self-regulation, scaffolding, and ZPD will be discussed in the context of the influencing interpretation work of these theories by Donato (1994) and Lantolf and Appel (1994).

\subsection{Self-Regulation}

Self-regulatory mechanism is regarded as one of the two types of metacognition in human mental activity, which is concerned with on-going attempts to solve problems. The other type is related to conscious reflection of one's cognitive abilities (Frawley \& Lantolf, 1985). Self-regulation in solving problems is also called 'strategic activity' by some researchers (Wertsch 1980a, as cited in Frawley \& Lantolf, 1985). According to Vygotsky (1978), children learn to engage in activity as an individual in social interactions between themselves and peers or more experienced members of the same culture. Gradually, children acquire conscious control and individuality through three levels of regulation in interaction known as object regulation, other regulation, and self-regulation.

The first stage, object regulation, refers to the process in which a person is controlled directly by environment and his/her attention is focused on objects that dominate cognition at that moment. At this stage, people are not able to exert control over the environment that instead influences them at the early stage of mental development. Furthermore, as some research (e.g. Wertsch \& Hickmann, 1987) shows, even if children are able to carry out tasks by themselves, they are not able to pursue independent action whenever a particular goal is not 'directly suggested by the environment' (Wertsch, 1979b, p. 89).

The second stage is other regulation, a process in which a person is regulated by another more knowledgeable or experienced person (e.g. adult, peer, and teacher) in the shared social activity. At this stage, people are able to carry out some tasks with linguistically mediated assistance from a parent, teacher, or more capable peer. This linguistically mediated assistance normally refers to dialogic speech that is regarded as the primary means of carrying out other-regulation (Wertsch, 1979a, 1979b, as cited in Frawley \& Lantolf, 1985). Later, Foley (1991) claims that non-linguistic features such as facial gestures should also be considered as mediated assistance.

Mitchell and Myles (1998) uses the term 'autonomous functioning' to mean the same thing, that is, the control of one's behavior does not 'reside on immediate stimuli (object regulation) or in another person (other regulation); instead, it is in an internally self-generated cognitive plan' (Antón, 1999, p. 83). However, it is noted that self-regulation is a relative phenomenon because the person is not necessarily self-regulated in a number of different tasks and not all people acquire self-regulation mechanisms for the same task at the same time. From the discussion of three levels of regulation, it can be seen that self-regulation comes after or because of regulation by others. This is a behavioral process (DeVries, 2000). This concept shows a complete contrast to the 'self-regulation' view presented by Piagetians from the psychological perspective. According to the summary from DeVries, for Piagetians, self-regulation already exists in early infancy. Therefore, self-regulation can be promoted by giving children extensive opportunities to make choices and decisions. Piagetians maintain that 
regulation by others may hinder children's self-regulation.

Some researchers apply Vygotsky's framework of self-regulation in first language acquisition to EFL/ESL language classrooms. For example, Foley $(1991$, p. 68) claims that the traditional type of EFL/ESL teaching is actually dominated by object-regulation or/and other regulation, that is, students are regulated by texts, exercises, or other-regulated by teachers. Upon analysis of Foley, it is agreeable that in traditional language classrooms, teachers tend to force learners to speak or write while self-regulation is not permitted when they are using the target language. Long and Crookes (1987, as cited in Foley, 1991) pointed out that traditional language teachers allow for little two-way interaction, while in the natural settings, speakers self-regulate through the complete interaction.

\subsection{The Zone of Proximal Development}

The Zone of Proximal Development is the place where the transition from other regulation, or inter-mental activity, to self-regulation, or intra-mental activity happens (Lantolf \& Appel, 1994, p. 12). According to Vygotsky, the concept of ZPD is defined as:

'the distance between the actual development level as determined by independent problem solving and the level of potential development as determined though problem solving under adult guidance or in collaboration with more capable peers.' $(1978$, p. 86)

According to this definition, Vygotsky established two developmental levels in the learner. One is the actual developmental level determined by actual ability without help from others, and the other is the potential level of development that refers to the ability when learners are offered assistances from others (De Guerrero \& Villamil, 2000)

For Vygotsky (1978, p. 90), one of the features of learning is that it creates ZPD. In other words, learning helps awaken a number of different developmental processes that can operate only during children's interaction with adults or peers. Once these processes are internalized, they become part of the independent development achievement. During the processes, Lantolf and Appel (1994) argue that adults set out to instruct children to solve problems strategically and adjust their feedback until they are capable of carrying out the required tasks independently without realizing that they are actually involved in a strategic activity. However, it is noted that in working within ZPD, it is not the successful completion of tasks that is of importance, but 'the higher cognitive process that emerges as a result of the interaction' (Lantolf \& Appel, 1994, p. 10). Furthermore, researchers (e.g. van Lier, 1996) claim that interaction or dialogic process between the novice and more experienced participant is considered a mutual win. This mutual win manifests because the novice gets guidance and support from the experienced that benefits from the social interaction. This social interaction helps the experienced internalize the strategic processes they need to examine closely what is easy or difficult for the novice to understand, guided by 'a long-term sense of direction and continuity, a local plan of action, and a moment-to-moment interactional decision-making' (van Lier, 1996, p. 199).

Some research shows that ZPD is also useful in L2 learning situations (Antón, 1999), although the concept of ZPD and relevant studies were conducted in situations of L1 acquisition or learning. With reference to SLL, Ohta defines ZPD as:

'the difference between the L2 learner's development level as determined by independent language use, and the higher level of potential development as determined by how language is used in collaboration with a more capable interlocutor' (1995, p. 96).

Furthermore, the original concept of ZPD was expanded beyond novice-expert interaction by L2 researchers (e.g. Donato, 1994; Ohta, 1995; Swain \& Lapkin, 1998). They claim that assistance can be provided equally between non-expert language learners through collaborative learning. In the study done by Nyikos and Hashimoto (1997), they expand the notion of ZPD to a group dynamic. In the study, they presented diaries from numerous individuals documenting their development within ZPD and presumed that the growth of one or more individual ZPDs in one group will lead to the development of that group zone as well, and vice versa. However, it is still arguable whether the evidence showing individual development in ZPD can demonstrate the same trend of the group zone, which involves many variables of other individual ZPDs. The researchers do not mention how to measure group ZPD. Is it according to one individual or a majority of ZPDs in a particular group? Furthermore, the evidence in this study is assessed using individual diaries, which is still controversial with respect to its appropriateness within this field. This leads to the research methods used in ZPD studies, which will be addressed next. 
According to Allal and Ducrey (2000), there are two contrasting ways of measuring ZPD originating from two different interpretations of Vygotsky's idea of this concept. One is aimed at measuring learner ZPD as an individual trait showing certain stability across instructional settings. On the other hand, the idea of assessment is carried out within ZPD created by learner on-going interaction with an instructional environment. Due to the two different versions of interpretations, there appear various ways to measure ZPD. Though the issue of how to assess ZPD is significant for ZPD research, there is still no agreement on the 'appropriate' way, which should be explored in future studies.

\subsection{Scaffolding}

Commonly, it is agreed that Vygotskian socio-cultural psychology and the notion of ZPD are at the heart of the concept of scaffolding (Krause et al., 2003; McDevitt \& Ormrod, 2002). However, the views of the exact ways in which ZPD and scaffolding relate to each other differ (Verenikina, 2003). Wells (1999) argues that scaffolding is an implication and operationalization of teaching in ZPD, whereas Daniels (2001) claims that scaffolding only partially reflects the richness of the notion of ZPD. In the following paragraphs, this notion of scaffolding will be analyzed from the perspectives of its definition and quality.

'Scaffolding' was first considered as a metaphor for mothers to maintain conversation with a child and to promote language acquisition (Bruner, 1978). Donato (1994) defines it as a dialogically constituted inter-psychological mechanism that elevates the novice's internalization of knowledge co-constructed in shared activity. According to this definition and Wells (1999, p. 127), 'scaffolding' possesses three particular features, according to which are, the dialogic discourse in which knowledge is con-constructed, the activity in which knowing is embedded, and the role of artifacts that mediate knowing. Furthermore, the metaphor of scaffolding was extended in educational psychology, referring to the process by which teachers or more capable peers help the less skilled solve problems. Later, some researchers (e.g. Greening, 1998) used this concept as a broad term to cover all forms of learning support and a wide range of services provided for learning.

The quality of scaffolding applied in education has been a big concern for many researchers (e.g., Bodrova \& Leong, 1996). It is necessary to define the criteria of a scaffolded help and a successful scaffolded performance. Mercer and Fisher (1993, as cited in Wells, 1999, p. 221) propose the following criteria of a scaffolded help, which should a) enable learners to carry out tasks that they themselves would not have been able to manage; $b$ ) be intended to bring learners to a state of competence that will enable them eventually to complete tasks on their own; and c) be followed by evidence of learners having achieved some greater level of independent competence as a result of scaffolding. Suggested from the characteristics of scaffolding behaviors by mothers, Wood, Bruner, and Ross (1976) hypothesize six features of successful scaffolding carried out by teachers/more-capable peers. These six features include (a) recruiting the tutee's attention, (b) reducing degrees of freedom in the task in order to make it manageable, (c) keeping direction in terms of goals, (d) marking critical features, (e) controlling frustration, and (f) modeling solutions. Wood, Bruner, and Ross further claim that carrying out successful scaffolded help depends on how skillfully the teachers/more-capable peers manage the interaction between tasks and the demands of less-skilled learners.

\section{Evaluation of Sociocultural Theory}

SCT is a 'new' approach in the field of education compared with other approaches such as behaviorism and cognitive approach. However, it has influenced and enriched greatly our understanding of SLL and actual teaching and learning practice. In this section, critical justifications of research findings will be presented. Relevant studies on the above-mentioned three concepts will be discussed first, followed by an evaluation of SCT as a whole from the perspectives of its contributions to SLL and limitations, based on Mitchell and Myles (1998).

Significant research has gone towards trying to understand the actual developmental process of learners from other regulation to self-regulation. One notable example, collected in Aljaafreh and Lantolf's article (1994) states that during the mutual knowledge building of tense markings for modal + main verb constructions, the teacher provides the students with more explicit feedback first. This article goes on to state that this idea even models the correct way of using modal auxiliary, and then the teacher gradually reduces help, only drawing the student's attention to the incorrect forms until he/she is able to correct the mistake. Aljaafreh and Lantolf argue that the reduced need for other regulation actually illustrates microgentic development with the learner's ZPD.

Numerous articles demonstrated that scaffolding can be successfully conducted by teachers or peers, and research attempted to prove that scaffolding could assist cognitive development of learners. For instance, Donato's study (1994) claims that peer-scaffolding results in linguistic development within the individual and those learners can expand their own L2 knowledge and extend the linguistic development of their peers, which 
have been proven by the microgenetic analysis of collaborative dialogic events and recorded oral activity. However, it is noted that teacher-student/student-student scaffolding is not likely to be carried out in all educational contexts until certain conditions are met. Drawing from some research (Donovan \& Smolkin, 2002; Verenikina, 2003; Antón, 1999), the following points should be taken into account. Firstly, teachers should not interpret scaffolding as direct instruction. Teachers may perceive that teacher-student interaction is driven predominately by the adult. In that case, the misunderstood assumption of scaffolding might lead to counterproductive hindering of children/learner's development. Secondly, language classrooms need to be learner-centered rather than teacher-centered. Only in learner-centered classrooms do students have more opportunity to involve in providing scaffolding and share responsibility for learning.

There are a number of contributions of SCT (particularly Vygotsky's theory) to SLA. Firstly, with the introduction of the conception of 'mediation', language teachers realize the importance of conceptualizing language learning as a process mediated by different kinds of semiotic sources in the classroom. Secondly, this theory helps teachers understand students from a different perspective, one that sees that students actually bring their own cultures to the interactions as learners because they have developed their understanding and individuality through interacting with people from culture communities they belong. Thirdly, sociocultural theory emphasizes that learning, including SLL, is actually situated, which means learning can occur in different places in various forms. Additionally, the conceptions of ZPD and Scaffolding are important in SLL because they help teachers comprehend that learner potential development can be achieved using a mediator and assisted help from teachers and peers. Besides these, there are other significant concepts that were adopted by researchers, such as private/inner speech and activity theory. All these concepts have been explored within EFL/ESL contexts and inspired a number of current popular approaches including for instance, task-based learning, and the collaborative approach.

So far, the discussions of SCT are based mainly on Vygotsky's theory. Nevertheless, it is highlighted that some differences exist between the contemporary sociocultural theory approach and Vygotsky's theory. For instance, according to Matusov and Hayes (2000, p. 216), Vygotsky saw development as a decreasing gap between mental functions of the individual's actions and norms, and he focused on what mental functions an individual 'brings to' or 'takes from' the activity. This led to a dualism between the individual and the social. From the sociocultural perspective, theorists claim that social is a combination of human activity and other aspects, such as individual, cultural, and historical, rather than simply an individual's environment or plane of actions.

Finally, this work discusses the limitations of SCT from the perspectives of the theory itself and the research studies previously conducted, drawing from the summary of Mitcell and Myles (1998). SCT has been applied to a wide range of aspects of SLL, from the acquisition of lexis to the development of learning strategies. Nevertheless, some aspects cannot be clearly explained within the sociocultural perspective. For example, as some researchers (e.g. Newman, Griffin, \& Cole, 1989, as cited in Donato, 1994, p. 35) have already pointed out, SCT cannot be used to examine inter-language grammar that remains an abstract process in the heads of individuals rather than concretely available in the social relationships among learners. Another limitation of Vygotsky's theory and the contemporary SCT is that it says little about biological contributions to children's development and their own capacity to shape their cognitive development (Berk, 2002).

This work will highlight three research limitations. First, the studies that have been conducted are rather small in scale and some of the studies do not present a complete picture of the study focus. For instance, Donato (1994) claims that the studies on L2 interactions do not present the evidence of cooperative actions that are claimed to be of importance in peer problem solving activities. Moreover, it is a pity that some research cannot clearly present the convincing results due to the choice of research methods. For example, Nyikos and Hashimoto's study (1997) looks for evidence from learner diaries that only describe the learners own feelings of 'making achievement' rather than presenting more reliable results demonstrating learner achievement of independent competence within ZPD. Finally yet importantly, other studies do not provide longitude research. For example, Aljaafreh and Lantolf's research (1994), which seems to not be convincing enough as Aljaafreh and Lantolf (1994) themselves and Vygotsky (1986) claim that the relationship between interaction and language development is not smooth and linear. Therefore, sociocultural theorists need to figure out the appropriate research methods to examine relevant studies.

\section{Implications of Sociocultural Theory}

One major implication of sociocultural theory is that it provides the psycholinguistic framework for a number of approaches (e.g. task-based learning and collaborative learning). Nun (2001) argues that five concepts of SCT are coinciding with task-based learning including mediation, activity theory, private speech, regulation, and ZPD. 
These components are implied to analyze learners and teachers under tasks in classroom activities. Moreover, Nun $(2001$, p. 7) continues to claim that there is a close correlation between task-based learning and SCT in the three perspectives of recontextualizing the classroom, considering activity or tasks as a place for learning and developing language, and focusing on meaning. As for collaborative learning, Swain (2000) claims that this approach reflects some of the key points in SCT including ZPD and scaffolding. To be more specific, collaborative learning heightens the potential for exploration of the learner's ZPD, mediates joint problem solving and knowledge building, and emphasizes language use mediating language learning. Another major implication of SCT is that it inspired some research into teaching techniques for a number of particular aspects including writing. From sociocultural perspective, writing is considered as 'a contextually situated social and cultural practice' (Vollmer, 2002, p. 1). Vollmer points out those teachers can guide students to discuss what they would like to adopt and avoid from source texts, which can help students develop critical awareness enabling them to increase their control over written discourse.

In this section, the implications of SCT will be investigated in the Chinese context with particular focus on teacher-student collaboration in the language classroom settings by assessing the applicability of collaborative learning. The reason for focusing on collaborative learning is that it is more familiar to Chinese teachers of EFL since education projects have been proposed to promote it in Chinese EFL classrooms (Fenwick, 2001). In the following paragraphs, this work shall first briefly introduce collaborative learning, followed by analyzing the Chinese context. Questions will then be raised based on this researcher's personal teaching experience in China.

Collaborative learning or collaborative dialogue (Swain, 2000), refers to interactions in which teacher-students/student-student are jointly engaged in problem solving and knowledge building. This notion has been implied in SLL and teaching in terms of mutual knowledge construction with teachers and learning through working with peers in pair work or group activity. This paper is interested particularly in the teacher/student collaboration. In the process of teacher-student collaboration, the main job of the teacher is assisting student performance through ZPD (Tharp \& Gallimore, 1988). Within ZPD, teachers control student's behavior (other-regulation) until they become self-regulated and eventually their performances become automated. Furthermore, through this kind of collaboration, teachers help students gain an awareness (and the requisite skills) of the need to continue to learn English by themselves when they leave classroom (Wenden \& Rubin, 1987, p. 9, as cited in Horwitz et al., 1997).

Theoretically, this approach appears to be ideal since it can enhance the effectiveness of classroom language teaching and learning and creates more learning opportunities through interaction, participation and negotiation (van Lier, 1991). The interactions and negotiation for meaning are of great significance for SLA and SLL since they can promote comprehension input and language acquisition (Long, 1983). Moreover, social constructivists believe that interaction is a prerequisite for engaging in self-regulation and a prior condition to learning and cognitive development (Vygotsky, 1978). However, it is still questionable as to whether social-constructivist beliefs underlying collaborative learning, such as acculturating students into a learning community and negotiating the ZPD in a social context, can be accepted by all countries, particularly China (Oxford, 1997). Theoretically, these beliefs can be accepted by the current Chinese society, since it is a socialist state similar to the state where Vygotsky was living and promoting his theory, and it is based on the communist ideology emphasizing collective help and equalization of personal relationships. Nevertheless, it is noted that present Chinese teaching and learning have been influenced by Chinese traditional culture. It seems hard for Chinese teachers and learners to accept the beliefs or approaches embedded by their beliefs.

For a long time, most Chinese language classrooms were dominated by traditional approaches where teaching was perceived as the transmission of knowledge from the teacher to the passive learner (Scollon, 1999). In Chinese hierarchical society, teachers are considered as the authority in the classrooms. The students listen carefully and do as teachers say so that knowledge can be transmitted. In such classrooms, teacher-student interaction is minimal and dominated by teachers (Larsen-Freeman, 1986). According to the Chinese culture of teaching and learning, there are some obvious constraints of employing collaborative approach and accepting socio-cultural beliefs. The constraints are mainly from two perspectives, the perceived way of learning in class and teacher anxiety of how to conduct collaboration that they might previously have never experienced. Chinese learners from an educational system that emphasizes respect for authority may feel uncomfortable learning in collaboration with the teacher, particularly when co-constructing knowledge with teachers in a more self-directed learning context (Wilhelm, 1997). Once learners are included in the learning community, they become constructors of knowledge as well as teachers, rather than knowledge receivers. According to this researcher's personal experience, supported by other researchers (Jin \& Cortazzi, 1998), Chinese students may find it hard to change their perceived role as a receiver and thus they may feel more hesitant to share their responses in the 
learning process. Second, teacher anxiety with respect to employing SCT comes from the following two reasons (1) as most teachers experienced the traditional teacher-centered methodology, it is quite possible that they tend to teach as they were taught (Simmons, 1995; as cited in Wilhelm, 1997), and (2) teachers may not be prepared to foster a collaborative relationship as some of them have not experienced collaboration in their own language learning experience (Horwitz et al., 1997).

Drawing from the above discussion, in order to implement collaborative learning, Chinese teachers should have some knowledge and experience in collaborative learning and its underlying philosophical principles. In addition, learners should change their traditional way of learning and get involved in the learning community in language classrooms. Although it is difficult to meet the conditions, Chinese teachers should hold an optimistic view regarding the possible application of collaborative learning. To overcome the constraint from the teacher perspective and lack of experience of collaborative learning, researchers (e.g. Wilhelm, 1997) claim that one solution is to conduct training programs for in-service and perspective teachers, through which they will be exposed to collaborative and learner-centered techniques in the role of learners. Wilhelm emphasizes the importance to create teaching/learning context for the teachers to put theory into practice rather than just learning the theory. This kind of training programs can offer learners support and guidance required to provide successful transitions into the actual collaborative language teaching or learning context. However, it should be noted that there is little literature about a workable model or training program for language teachers; even the program mentioned in Wilhelm's article is problematic as he himself claims. Therefore, future explorations in this area need to be conducted.

It is noted that current Chinese student views of learning are changing. According to Zhao's study (2010), 40\% of Chinese language learners prefer the way of learning based on teacher/student discussion and negotiation, and $20 \%$ prefer learning through asking-answering questions. It is obvious that a larger proportion of learners want to be in learner-centered environment. Though the number of students in Zhao's study ( $\mathrm{n}=100)$ cannot represent 60 million learners in China, many more studies need to be carried out. Zhao's study does indicate that language learners might be mentally ready for the change of learning and teaching style. Moreover, Tang (2012) reported that Chinese researchers already realized the necessary change of the traditional relationship that has hindered applying the new approaches, and are in turn making efforts suggest development of a collaborative relationship to enhance learning effectiveness.

\section{Conclusion}

This paper attempted to explore SCT through thorough discussion of Vygotsky's three concepts, critical evaluation of SCT and further examination of SCT by assessing collaborative learning within the Chinese context. This paper concluded that the perceived way of learning and teacher-student relationship should be changed in order to carry out teacher-student collaboration. Although this paper presented evidence showing the possibility of and some sort of readiness for employing collaborative learning, further studies after applying the New Standards are needed.

\section{References}

Aljaafreh, A., \& Lantolf, J. P. (1994). Negative feedback as regulation and second language learning in the zone of proximal development. The Modern Language Journal, 78(4), 465-483. http://dx.doi.org/10.1111/j.1540-4781.1994.tb02064.x

Allal, L., \& Ducrey, G. P. (2000). Assessment of-or in the zone of proximal development. Learning and Instruction, 10, 137-152. http://dx.doi.org/10.1016/S0959-4752(99)00025-0

Antón, M. (1999). The discourse of a learner-centered classroom: sociocultural perspectives on teacher-learner interaction in the second language classroom. The Modern Language Journal, 83(3), 303-318. http://dx.doi.org/10.1111/0026-7902.00024

Berk, L. E. (2002). Child Development (6th ed.). Boston, MA; London: Allyn \& Bacon.

Bodrova, E., \& Leong, D. J. (1996). Tools of the Mind: The Vygotskian Approach to Early Childhood Education. Englewood Cliffs, NJ: Merrill/Prentice Hall.

Bruner, J. S. (1978). The role of dialogue in language acquisition. In A. Sinclair, R. J. Jarvelle, \& W. J. M. Levelt (Eds.), The Child's Concept of Language (pp. 241-256). New York: Springer-Verlag.

Byram, M., \& Fleming, M. (Eds.). (1998). Language Learning In Intercultural Perspective: Approaches Through Drama and Ethnography. Cambridge, England: Cambridge University Press.

Cheng, Xue (2012). Dui yingyu de sikao. Retrieved from http://www.ecp.com.cn/in2004/ca2605.htm 
Daniels, H. (2001). Vygotsky and Pedagogy. NY: Routledge / Falmer.

De Guerrero, M. C. M., \& Villamil, O. S. (2000). Activating the ZPD: Mutual scaffolding in L2 Peer Revision. The Modern Language Journal, 84(1), 51-68. http://dx.doi.org/10.1111/0026-7902.00052

DeVries, R. (2000). Vygotsky, Piaget, and education: A reciprocal assimilation of theories and educational practices. New Ideas in Psychology, 18, 187-213. http://dx.doi.org/10.1016/S0732-118X(00)00008-8

Donato, R. (1994). Collective scaffolding in second language learning. In J. P. Lantolf, \& G. Appel (Eds), Vygotskian Approaches to Second Language Research (pp. 33-56). NJ: Ablex.

Donato, R. (2000). Sociocultural contributions to understanding the foreign and second language classroom. In J. P. Lantolf (Ed.), Sociocultural Theory and Second Language Learning (pp. 27-50). Oxford, England: Oxford University Press.

Donovan, C., \& Smolkin, L. (2002). Children's Genre Knowledge: An Examination of K-5 Students Performance on Multiple Tasks Providing Differing Levels of Scaffolding. Reading Research Quarterly Newark, 37(4), 428-465. http://dx.doi.org/10.1598/RRQ.37.4.5

Fenwick, T. J. (2001). Curriculum Building and Teacher Development: English Language Learning in China.

Foley, J. (1991). A psycholinguistic framework for task-based approaches to language teaching. Applied linguistics, 12(1), 62-75. http://dx.doi.org/10.1093/applin/12.1.62

Frawley, W., \& Lantolf, J. P. (1985). Second language discourse: A Vygotskian perspective. Applied Linguistics, 6(1), 19-44. http://dx.doi.org/10.1093/applin/6.1.19

Greening. T. (1998). Scaffolding for Success in Problem-Based Learning. Med Educ Online. http://dx.doi.org/10.3402/meo.v3i.4297

Hatch, E. (1978). Discourse analysis and second language acquisition. In E. Hatch (Ed.), Second Language Acquisition (pp. 401-435). Rowley, MA: Newbury House.

Hatch, E. (Ed.). (1978). Second Language Acquisition. Rowley, MA: Newbury House.

Hinkel, E. (Ed.). (1999). Culture in Second Language Teaching and Learning. Cambridge, England: Cambridge University Press.

Horwitz, E. K., Bresslau, B., Dryden, M., Mclendon, M. E., \& Yu, J. F. (1997). A graduate course focusing on the second language learner. The Modern Language Journal, 87(4), 518-526. http://dx.doi.org/10.1111/j.1540-4781.1997.tb05520.x

Jin, L. X., \& Cortazzi, M. (1998). The culture the learner brings: A bridge or a barrier? In M. Byram, \& M. Fleming (Eds.), Language Learning In Intercultural Perspective: Approaches Through Drama and Ethnography (pp. 98-118). Cambridge, England: Cambridge University Press.

Krause, K., Bochner, S., \& Duchesne, S. (2003). Educational Psychology for Learning and Teaching. Australia: Thomson.

Lantolf, J. P. (2000). Introducing sociocultural theory. In J. P. Lantolf (Ed.), Sociocultural Theory and Second Language Learning (pp. 1-26). Oxford, England: Oxford University Press.

Lantolf, J. P. (Ed.). (2000). Sociocultural Theory and Second Language Learning. Oxford, England: Oxford University Press.

Lantolf, J. P., \& Appel, G. (Eds.). (1994). Vygotskian Approaches to Second Language Research. NJ: Ablex.

Larsen-Freeman, D. (1986). Techniques and Principles in Language Teaching. New York: Oxford University Press.

Long, M. H. (1983). Linguistic and conversational adjustments to non-native speakers. Studies in Second Language Acquisition, 16, 283-302.

Long, M. H., \& Crookes, G. (1987). Units of analysis in syllabus design: unpublished manuscript. University of Hawaii at Manoa.

Luria, A. R. (1987). The Mind of a Mnemonimist. Cambridge, MA: Harvard University Press.

Matusov, E., \& Hayes, R. (2000). Sociocultural critique of Piaget and Vygotsky. New Ideas in Psychology, 18, 215-239. http://dx.doi.org/10.1016/S0732-118X(00)00009-X

McDevitt, T. M., \& Ormrod, J. E. (2002). Child Development and Education. Upper Saddle River, NJ: Merrill 
Prentice Hall.

Mercer, N., \& E. Fisher (1993). How do teachers help children to learn? Learning and Instruction, 2(4), 339-355. http://dx.doi.org/10.1016/0959-4752(92)90022-E

Mitchell, R., \& Myles, F. (1998). Second Language Learning Theories. London, England: Arnold.

Newman, D., Griffin, P., \& Cole, M. (1989). The Construction Zone: Working for Cognitive Change in School. Cambridge, England: Cambridge University Press.

Nun, B. (2001). Task-Based Methodology and Sociocultural Theory.

Nyikos, M., \& Hashimoto, R. (1997). Constructivist theory applied to collaborative learning in teacher education: In search of ZPD. The Modern Language Journal, 81(4), 506-517. http://dx.doi.org/10.1111/j.1540-4781.1997.tb05518.x

Ohta, A. (1995). Applying sociocultural theory to an analysis of learner discourse: learner-learner collaborative interaction in the zone of proximal development. Issues in Applied Linguistics, 6(2), 93-121.

Oxford, R. (1997). Cooperative learning, collaborative learning, and interaction: Three communicative strands in the language classroom. The Modern Language Journal, 81(4), 443-456. http://dx.doi.org/10.1111/j.1540-4781.1997.tb05510.x

Scollon, S. (1999). Not to waste words or students: Confucian and Socratic discourse in the tertiary classroom. In E. Hinkel (Ed.) (1999). Culture in Second Language Teaching and Learning (pp. 13-27). Cambridge, England: Cambridge University Press.

Simmons, S. (1995). The teacher education program consortium: A new network for professional development in experiential education. The Journal of Experiential Education, 18(3), 120-127. http://dx.doi.org/10.1177/105382599501800302

Sinclair, A, Jarvelle, R. J. \& Levelt W. J. M. (Eds.). (1978). The Child's Concept of Language. New York: Springer-Verlag. http://dx.doi.org/10.1007/978-3-642-67155-5

Swain, M. (2000). The output hypothesis and beyond: Mediation acquisition through collaborative dialogue. In J. P. Lantolf (Ed.), Sociocultural Theory and Second Language Learning (pp. 97-114). Oxford, England: Oxford University Press.

Swain, M., \& Lapkin, S. (1998). Interaction and second language learning: Two adolescent French immersion students working together. The Modern Language Journal, 83, 320-338. http://dx.doi.org/10.1111/j.1540-4781.1998.tb01209.x

Tang, Ning. (2012). Suzhi jiaoyu de guanjian shi shisheng guanxi. Retrieved from http://ax.edu.qz.fj.cn/jyyj/szjy.htm

Tharp, R. G., \& Gallimore, R. (1988). Rousing Minds to Life: Teaching, Learning, and Schooling in Social Context. New York, NY: Cambridge University Press.

Van Lier, L. (1991). Inside the classroom: learning processes and teaching procedures. Applied Language Learning, 2, 29-68.

Van Lier, L. (1996). Interaction in the Language Curriculum: Awareness, Autonomy and Authenticity. New York: Longman.

Verenikina, I. (2003). Understanding scaffolding and the ZPD in educational research. AARE 2003 Conference Papers. Retrieved from http://www.aare.edu.au/03pap/ver03682.pdf

Vollmer, G. (2002). Sociocultural Perspectives on Second Language Writing. ERIC/CLL Newsbulletin, 25(2), $1-2$.

Vygotsky, L. S. (1978). Mind in Society. Cambridge, MA: Harvard University Press.

Vygotsky, L. S. (1986). Thought and Language. Cambridge, MA: MIT Press.

Wells, G. (1999). Dialogic Inquiry: Towards a Sociocultural Practice and Theory of Education. New York: Cambridge University Press. http://dx.doi.org/10.1017/CBO9780511605895

Wenden, A., \& Rubin, J. (1987). Learner Strategies in Language Learning. New York: Prentice Hall.

Wertsch, J. V. (1979a). From social interaction to higher psychological processes: A clarification and application of Vygotsky's theory. Human Development, 1, 15-18. 
Wertsch, J. V. (1979b). The Regulation of Human Action and the Given-new Organization of Private Speech. New York: J. Wiley and Sons.

Wertsch, J. V. (1980a). Adult-child interaction as a source f self-regulation in children. Paper presented at conference on the growth of insight during childhood. University of Wisconsin.

Wertsch, J. V., \& Hickmann, M. (1987). Problem-solving in social interaction: A microgenetic analysis. In M. Hickmann (Ed.), Social and Functional Approaches to Language and Thought (pp. 251-265). Orlando, FL: Academic Press.

Wilhelm, K. H. (1997). Sometimes kicking and screaming: language teachers-in-training react to a collaborative learning model. The Modern Language Journal, 827-542. http://dx.doi.org/10.1111/j.1540-4781.1997.tb05522.x

Wood, D., Bruner, J. S., \& Ross, G. (1976). The role of tutoring in problem-solving. Journal of Child Psychology and Child Psychiatry, 17, 89-100. http://dx.doi.org/10.1111/j.1469-7610.1976.tb00381.x

Zhao, Xueping (2010). Waiyu jiaoxue buke hushi renzhi de zhongyaoxing. Retrieved from http://www.tefl-china.net/111.htm

\section{Copyrights}

Copyright for this article is retained by the author(s), with first publication rights granted to the journal.

This is an open-access article distributed under the terms and conditions of the Creative Commons Attribution license (http://creativecommons.org/licenses/by/3.0/). 